\title{
Events, events! ...a perspective from the British Mass Spectrometry Society
}

\author{
Mark A. McDowall
}

The British Mass Spectrometry Society, c/o 25 Burwardsley Way, Northwich, Cheshire, CW9 8WN, UK. mark_mcdowall@icloud.com

Harold Macmillan (British Prime Minister 1957-1963), when asked to name the most difficult thing about his job, responded (patricianly); "events, dear boy, events!". The pandemic events of 2020 have had far reaching consequences for British Mass Spectrometry Society (BMSS) committee members both personally and professionally. In Covidious Albion, the BMSS's diary of scientific meetings was obliterated and we have all had to adapt to interacting via Zoom.

\section{What are the realistic prospects for analogue scientific meetings in 2021?}

The rollout of efficacious vaccines and the social imperative bodes well for the resumption of conventional meetings. However, the unknown unknowns of new COVID-19 variants coupled with the tightening of public and private sector budgets may allow only a modest revival of events in the latter half of this year.

"There are decades where nothing happens; and there are weeks where decades happen." "The COVID-19 rollercoaster, for the BMSS Events Team,

\section{DOI: $10.1255 /$ sew.2021.a3}

(c) 2021 The Author

Published under a Creative Commons BY licence

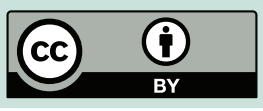

began on 16 March 2020 with the first onset of lockdown in the UK. In the following months we all began to grasp the enormity of the situation, with the inevitable cancellation of a succession of one-day Special Interest Group (SIG) events and finally the abandonment of our financially critical three-day Annual Meeting scheduled for September 2020.

Since its foundation in 1964, the British Mass Spectrometry Society has progressively developed a programme of charitable disbursements. The Society's income and expenditure has for decades balanced on the knife-edge of a modest surplus generated from its traditional three-day Annual Meeting.

The BMSS took the view that its ethical response to COVID-19 should be to strive to keep the public discourse of mass spectrometry alive in the UK. The Society also thought it important to provide a platform for Early Career Researchers (ECRs) to present their work in the virtual space. Over the following months we collaborated with fantastic teams of SIG coordinators and sibling societies (e.g. the Mass Spectrometry Imaging Society) to deliver a programme of 26 on-line events to the mass spectrometry community at large. ${ }^{2}$

Going virtual has had significant benefits: we now have regular participants in our on-line events that range from Singapore in the east to Los Angeles in the west, from Auckland in the south to Stockholm in the north. We have made many new friends and they are a very welcome addition to the BMSS family. The downside is that, whilst we have made many new friends, we have struggled to develop an income stream to sustain the Society's charitable disbursements.

So, the critical challenge that faces many scientific societies in the short term is how to evolve a new funding model for the COVID-19 era that both serves the needs of members and delivers value to sponsors. We detect a marked resistance to charging delegates a significant fee for on-line events. We have all become accustomed to streaming unlimited entertainment (e.g. Netflix etc.) for a negligible monthly subscription, and that has set cultural expectations. We anticipate that inviting on-line delegates to make a donation (cf. the Wikipedia funding model) will only yield a very modest revenue and will not balance the books!

Feedback from our traditional sponsors (i.e. scientific instrument companies and scientific service providers) suggests that they are challenged to justify return on investment (ROI) when invited to support virtual events.

\section{Will virtual events become adopted as the new normal?}

In general, there is a human propensity to be wary of change. In this instance we think that that predilection will prevail, and that the overriding social imperative will triumph in the short term.

Necessity is the mother of invention! The pandemic has stimulated a multiplicity of innovations for the virtual hosting of major events (e.g. iVent, ${ }^{3}$ vFairs ${ }^{4}$ etc.). These solutions are fantastic but will not, in our opinion, replace the roar of the bar and smell of the crowd. We expect that 
the social imperative will prevail when public health restrictions abate, and so major traditional events will revive in the short to medium term.

The immediacy of personal interaction, the subtlety of subliminally observed body language and the sheer pleasure of doing business face-to-face will not be superseded by virtual conferencing in short order. So, the preferred option for major events will be strictly analogue in the foreseeable future.

Small virtual events (e.g. SIG meetings via Zoom), lasting no more than a couple of hours, have and are being adopted as positive enhancements to the scientific landscape and are likely to become enduring fixtures in our diaries long after the pandemic has been brought under control.

\section{The roar of the bar and} the smell of the crowd! The social imperative impels us to seek out the company of our peers, to vigorously discuss our science face-to-face and engage in networking events. The desire of our community to resume traditional events, in the short term, is undeniable.

Simulating major events on-line, with current technology, has little traction with either prospective delegates or sponsors! Our members are resolute in their wish to see traditional analogue events revived. Our sponsors have made it clear that supporting virtual events is very hard for them to justify on the basis of ROI,

.. and we do not detect that that view is softening.

The BMSS conducted a member and community e-survey in March 2020: Adapting to the Challenge. ${ }^{5}$ The objective was to gauge the community appetite for a virtual alternative to the Society's classic three-day Annual Meeting scheduled for September 2020. The results were illuminating; a small subset of enthusiastic members was very much in favour, the majority were agnostic and, most chillingly, the majority of the Society's sponsors and supporters were very sceptical. So, in light of the received feedback the Society elected to eschew a virtual alternate to its classic Annual Meeting in 2020.
Imagineering a low carbon event culture ca 2031

Project yourself forward a decade to a time where the internal combustion engine has become a relic, your home will be heated by a super-efficient heat pump, broadband of gargantuan bandwidth is universally available and carbonhungry air travel will be déclassé.

In 2031, technology permitting, we may be able to readily engage in satisfyingly holistic and holographically virtual event experiences. The combination of most institutions' inclination to cut travel budgets (whenever a pretext arises), and the leading nations' stated intent to extinguish their carbon footprints may prefigure the twilight of the traditional international scientific meeting.

In 2031, only the elite of our community may be invited/permitted to travel (with appropriate carbon offsetting) to a glamorous location, conference with their peers and enjoy a tincture on the terrace before a terroir-specific dinner.

The privilege of encountering new science/colleagues/places/cultures/ foods at first hand (that was part and parcel of the traditional ECR's professional trajectory) may become the preserve of a very select few. This may have implications for social mobility and professional inclusion for a generation or more. We may see the emergence of a patrician old guard (underpinned by personal networks formed on the traces of grand hôtels in times past) competing with a younger and strictly virtual cohort. In the long term everything will come into equilibrium, in the medium term it may spawn a decade or more of unintended segmentation.

\section{Come fly with us...}

Attendance at international conferences (e.g. ASMS, IMSC etc.) has become part of our community's culture. As we all know, in response to the pandemic, most major airlines have mothballed or scrapped significant portions of their fleets (British Airway's Queen of the Skies 747-400, for example). The rollout of viable vaccines may well open the door to a renewed freedom to travel, and so unleash pent-up demand to do so!
It is possible that demand for seats my outstrip supply in the second half of 2021 and so ticket prices may be expected to rise.

The BMSS, and analogous societies, have established programmes to provide assistance to their members (typically ECRs) to facilitate their participation at international conferences. The projected increase in the price of air travel in the second half of 2021 combined with the paucity of charitable income in 2020 presents a cash flow challenge that we have all yet to rationalise.

\section{Looking to the immediate future with pragmatic realism}

Reviving traditional scientific events, within 2021, is fraught with challenges! The rollout of efficacious COVID-19 vaccines is fantastic news-however, that will not solve the scientific event organisers' challenge in 2021! Academic and corporate travel policies (and marketing budgets) were crystallised around the fourth quarter of 2020. Coming off the back of a tough year in 2020, budgets have been cut to the bone, and so prospective delegates and sponsors will be very hard to secure.

Being pragmatic, the BMSS will revive its Annual Meeting when circumstances permit. We are aggressively researching a modest 1.5-day event for September 2021 as a stepping-stone to a classic three-day meeting in 2022. The BMSS is most grateful to its members and sponsors for encouraging the Society on that challenging journey.

The path to reviving analogue scientific events in 2021 will be turbulent! The organisers involved may rationalise their experiences post facto as a rite of passage,

...fasten your seatbelts it's going to be a bumpy right!

\section{References}

1. Vladimir Ilyich Ulyanov 'Lenin' (Russian Head of Government, 1917-1924). https://www. goodreads.com/quotes/342783there-are-decades-where-nothinghappens-and-there-are-weeks 


\section{LARTGE-}

2. The British Mass Spectrometry Society. https://www.bmss.org.uk/ meetings/

3. iVent. https://www.ivent-uk.com/ conferences

4. vFairs. https://www.vfairs.com/

5. The British Mass Spectrometry Society. https://www.bmss.org.uk/ covid-19-adapting-to-the-challenge/

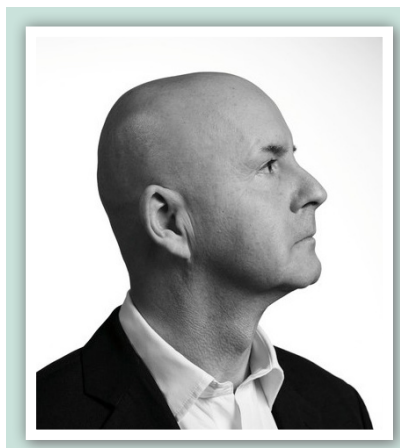

Dr Mark A. McDowall JP

Mark is the Meetings Secretary of the British Mass Spectrometry Society and a Trustee of the BMSS. Prior to retirement he held senior management roles in applications development, scientific marketing and business development at Waters Corporation, Micromass UK Limited and VG Instruments. 